\title{
Sources and Levels of Foreign Language Speaking Anxiety of English as a Foreign Language University Students with regard to Language Proficiency and Gender
}

\author{
Emre Debreli (Corresponding author) \\ Dr. Fazil Kucuk Faculty of Education, European University of Lefke \\ Gemikonagi, Lefke, Mersin 10 Turkey \\ Tel: 0090-660-2660 E-mail: edebreli@eul.edu.tr
}

\begin{abstract}
Seren Demirkan
English Preparatory School, European University of Lefke
\end{abstract}

Lefke, Mersin 10 Turkey

Tel: 0090-660-2861Ｅ-mail: sakmen@eul.edu.tr

Received: November 29, 2015 Accepted: December 12, 2015 Published: December 13, 2015

doi:10.5296/ijele.v4i1.8715 URL: http://dx.doi.org/10.5296/ijele.v4i1.8715

\begin{abstract}
Although foreign language anxiety is a widely explored subject in the area of English as a Foreign Language (EFL), studies that focus on the speaking anxiety in EFL, as well as the gender and language proficiency level-anxiety relationship, are rare. The present study investigates the phenomenon in an EFL context and analyzes the levels of EFL students' speaking anxiety and the sources that make them anxious. It also explores whether there is any relationship between anxiety and students' language proficiency level and gender. Data were gathered from 196 Turkish and Turkish Cypriot students through questionnaires (Foreign Language Classroom Anxiety Scale), as well as through semi-structured interviews with 10 students who participated in the questionnaires. The findings indicated that the students generally had low level of speaking anxiety, although students with a higher level of language proficiency had a higher level of anxiety compared with that for students with a lower level of language proficiency. No
\end{abstract}


statistically meaningful difference was observed with regard to students' gender and anxiety levels. Factors that caused anxiety-such as difficulty in pronunciation, being asked immediate questions by the teacher, not understanding the question asked by the teacher-not found in the current literature also emerged from the present study. Implications for teacher education are also discussed.

Keywords: anxiety, English as a Foreign Language, speaking, Foreign Language Anxiety Scale, language learning

\section{Introduction}

Foreign language anxiety is one of the widely explored subjects in the area of language learning and teaching (Hedge, 2011; Horwitz, 2001). For years, predominant discussion has been on whether anxiety affects language learning. In this regard, many have found a strong link between anxiety and foreign language learning (i.e., Bless and Fiedler, 2006; Horwitz, 2001; Yule, 2006). A common perception exists that anxiety stands as a main block in succeeding foreign language, especially when it comes to speaking in the foreign language (Minghe and Yuan, 2013). Many factors causing anxiety when learning a foreign language have been noted (Worde, 2003). Regardless of the type of anxiety, it is often accepted that it affects individual's three functioning systems: cognitive, physical, and behavioral (Ormrod, 2005). These functioning systems are said to be activated together, that is, if a learner worries about speaking in front of the class (cognitive), he/she may start to experience physical symptoms (i.e., shaking), and he/she tries to avoid participating in the speaking activities in the following tasks (behavioral). Such inhibition of oral practice in the target language, for example, is often regarded by language professionals as a negative factor in language learning, as it is often taken for granted that language learning strongly depends on maximum exposure to practice in the target language. A commonly cited definition of language anxiety in the area of language research, perhaps more relevant to this paper, is put forth by Gardner and MacIntyre (1993: 5) "the apprehension experienced when a situation requires the use of a second language with which the individual is not fully proficient." A comprehensive list of factors causing language anxiety, based on the existing research, is discussed in the following section.

\subsection{Research on Foreign Language Anxiety}

Research to date on foreign language anxiety, particularly in speaking skill has revealed various factors that cause anxiety. Students in Worde's (2003) study, for example, listed factors causing anxiety as: speaking in front of others, inability to comprehend in the target language, fear of negative evaluation, and negative classroom experience. In Young's (1994) study, teachers' judgmental attitude was also another type of cause. Interaction with others (Ohata, 2005), unsympathetic teacher personality (Lucas, Mira, Flores, and Go, 2011), competitiveness in the classroom, and classroom personality (Williams and Andrade, 2008) are also other types of factors causing anxiety that exist in the literature. In terms of the effects of the anxiety in foreign language learning, the study by Arnaiz and Guillen (2012) in 
a Spanish university EFL context found that the students had a low level of anxiety related to speaking, but this still had a negative impact on the learning process by slowing down the development of the target language. A similar study conducted in China by Liu (2006) also revealed similar findings, but this study also addressed language proficiency-anxiety relationship as a possible factor in determining the anxiety level.

While there are a variety of different studies on foreign language anxiety (as mentioned above) and although much has been explored, the current research still strives for more studies on certain aspects. It appears that much is known on what factors cause anxiety and how they affect language learning. However, research on certain issues, especially the ones that are more related to students' demographic characteristics and their foreign language anxiety relationship, are rarely touched upon. More specifically, we know less, at least from an empirical perspective, about whether language proficiency level, or students' gender, has an influence on their foreign language anxiety while speaking in the target language. Considering such investigation as a possible contribution to the existing literature, the present study intends to examine a group of EFL students' sources and levels of foreign language anxiety, in particular concerning the speaking skill, relative to their target language proficiency level and gender. Factors that cause anxiety are also of interest.

\section{Method}

The present study implemented a mixed approach, that is, qualitative and quantitative approaches are used to gather data with the intention of increasing the richness of the data collected. Mixed method approach is a procedure for collecting, analyzing, and integrating both qualitative and quantitative approaches in a study to understand a research problem (Creswell, 2006). Through this method, the aim of the present study was to obtain numerical data that can be generalized to wider contexts as well as interpretative data for in-depth understanding of the phenomenon.

\subsection{Research Questions}

The present study intended to find answers to the following research questions:

- Do EFL students experience foreign language anxiety (FLA)? If so, what is the level of FLA?

- What makes EFL students most anxious?

- Do the EFL students' FLA levels vary according to their proficiency level and gender?

\subsection{Data Collection Instruments}

In the study, a questionnaire and semi-structured interviews were used to gather data. The intention here was to obtain data from the whole cohort through the questionnaire and a more detailed data through the semi-structured interviews by delving deeper with a lesser number of participants (Cresswell, 2006). The data obtained from two sources were then combined and crosschecked for validity purposes, as well as for increasing the richness of the findings. 


\section{2. 1 Questionnaire}

Questionnaires are the most commonly used research methods, as they are considered to be quick and simple when collecting data from a large group (Cohen, Manion, and Morrison, 2011). In the present study, they are used as the main data collection instrument. The Foreign Language Classroom Anxiety Scale (FLCAS), developed by Horwitz, Horwitz, and Cope (1986: 128), was used in the present study. However, since the level of the English language proficiency level of the participants who participated in the present study was low, a Turkish translated version of the questionnaire by Un (2012) was adopted. The questionnaire had two parts. In the first part, personal questions, such as age, gender, language proficiency level of the participants, were asked. In the second part, 33 questions on a 5-point Likert Scale were used. (See Appendix for the English version of the questionnaire used.)

\section{2. 2 Semi-structured interviews}

The second instrument used in the study was the semi-structured interview. The main reason behind selecting this instrument was to delve deeper into the participants' responses and to collect detailed data with regard to the participants' anxiety sources and levels. In line with this purpose, semi-structured interviews are known to have such characteristic, as they allow the researcher to ask follow-up questions and further probe the responses of the participants (Kvale, 2007). Four main interview questions were used to initiate the process, which were further supported by follow-up questions and probes.

\subsection{Participants}

In the present study, 196 students of the total 350 enrolled in the English Preparatory School of a university in Cyprus volunteered to participate. For ethical purposes, the name of the university has been kept confidential. The participating students were Turkish and Turkish Cypriots, whose mother tongue was Turkish. The participants had different English language proficiency levels. Demographic information about the participants is given in terms of frequency and percent of age, gender, and proficiency level, as shown in Table 1 below.

Table 1. Demographic information about the participants

\begin{tabular}{lll}
\hline & Frequency & Percent \\
\hline Age group & & \\
$18-22$ & 103 & 52.6 \\
$23-27$ & 65 & 33.2 \\
$28-32$ & 24 & 12.2 \\
33 and older & 4 & 2.0 \\
\hline Gender & & \\
Female & 57 & 29.1 \\
Male & 139 & 70.9 \\
\hline Proficiency Level & & \\
Elementary & 100 & 51.0 \\
Pre-intermediate & 96 & 49.0 \\
\hline Total & 196 & 100.00 \\
\hline
\end{tabular}


Distribution of the characteristics of the participants in the scope of the research is given in Table 1. When Table 1 is examined, it can be perceived that $52.6 \%$ of the participants who participated in the survey were between 18 and 22 years old, $33.2 \%$ of them were between 23 and 27 years old, $12.2 \%$ of them were between 28 and 32 years old, and $2 \%$ of them were 33 years older or older. Of the participants, $29.1 \%$ were female and $70.9 \%$ were male. When the proficiency levels of the participants are examined, it can be seen that $51 \%$ of them were at the elementary level, and $49 \%$ were at the pre-intermediate level.

\subsection{Data Collection Procedures}

After all the necessary permissions were granted, the process of data collection continued for two weeks. The day for administering the questionnaire was chosen according to the classroom teachers, and the day that best suited them was chosen so as not to interfere with the flow of their lesson plans. On the day of administration, the participants were informed about the purpose of the survey, and necessary instructions were given to them as to how to answer the questions. In order to help the participants answer the questions willingly and honestly, they were told that they did not have to provide their names and that the information they provided would have kept confidential.

After collecting the questionnaire data, days were arranged for the interviews with 10 randomly selected volunteer students from the ones who participated in the questionnaires. During the interviews, audio-recording was used. The interviews were conducted in the Turkish language to make the participants feel comfortable, as their English language levels were not sufficient enough to express their thoughts in English. The verbatim transcriptions of the interviews, which were in Turkish, were then translated into English by two experts, and both translations were checked for their consistency. At the end, an agreed translation model was developed for international use.

\subsection{Data Analysis}

The data obtained from the questionnaires were analyzed using Statistical Package for the Social Sciences (SPSS) version 16.0 for Windows Evaluation. A table of frequency is used as a tool to show the characteristics of the participants in terms of age, gender, and language proficiency level. In order to explore participants' level of anxiety, descriptive analysis was used. T-test was also applied to find out whether there is a significant difference between the participants' anxiety level and language proficiency level, as well as the gender.

Interview data analysis, on the other hand, was initiated by transcribing the audio-recorded data, which was followed by repeated reading sessions. After familiarizing with the data, codes were given to the data chunks (Miles and Huberman, 1994). The codes determined are then checked for similarities between them, and codes that went together were combined, which lead to categorization (ibid.). Two categories, namely, "EFL speaking anxiety" and "sources and reasons for speaking anxiety," emerged from the interview data.

\section{Findings and Discussion}

This section presents the findings of the present study obtained from the two data sources. 


\subsection{Findings from the Questionnaire Data}

This section presents only the questionnaire findings.

\subsubsection{EFL Students’ Anxiety Level (Research question 1)}

To measure the level of speaking anxiety, a questionnaire (FLCAS) consisting of 33 items was used. Since the questionnaire was a 5-point Likert scale, the total score ranged from 33 to 165 (one point for each item equals 33 points of minimum score in total, whereas five points for each item equals 165 of maximum score, based on the Likert scale grading). A total score of more than 132 was interpreted to demonstrate a high level of speaking anxiety, whereas a total score ranging from 99 to 132 demonstrated a moderate level of speaking anxiety, and a total score of less than 99 indicated a low level of foreign language speaking anxiety (Un, 2012). To determine the level of foreign language speaking anxiety of the participants, the mean scores were computed through descriptive statistics.

Table 2. Percentages and Frequencies of students' foreign language speaking anxiety

\begin{tabular}{lll}
\hline & Percentages & Frequencies \\
Low level of speaking anxiety & 55.61 & 109 \\
Moderate level of speaking & 41.32 & 81 \\
High level of speaking anxiety & 3.06 & 6 \\
\hline Total & 100 & 196 \\
\hline
\end{tabular}

The results presented in Table 2 reveal that the students at the program generally experience a low level of speaking anxiety. The descriptive results suggest that $55.61 \%$ of the participants scored less than 99, which indicates a low level of speaking anxiety, whereas $41.32 \%$ of them scored 99-132, which indicates a moderate level of speaking anxiety. In addition, $3.06 \%$ of them scored higher than 132, which indicates a high level of speaking anxiety. To put it differently, more than half of the students appeared to have low level of speaking anxiety. The reason for this result can be attributed to the awareness of the fact that speaking in foreign language is the key to securing their future in the faculty and also for finding a better job with a good salary in their country. In a study conducted in the Turkish EFL context by Öztürk and Gürbüz (2014), similar results were obtained from a cohort of 383 pre-intermediate level students. In another study conducted by Arnaiz and Guillén (2012) in a Spanish university context, the researchers found that the two-thirds of the 216 participants experienced moderate level anxiety (Arnaiz and Guillén, 2012). 
3.1.2 Reasons that Make EFL Sstudents Most Anxious (Research question 2)

The items of the questionnaire were related to six sources of foreign language anxiety: learning a particular language (items: 5, 6, 11, 16, 17, 22, 26, 28), foreign language performance (items: 1, 9, 14, 18, 24, 27, 30, 31, 32), making mistakes (items: 2, 13, 15, 19), being compared to fellow students (items: 7, 23), fear of failure (items: 4, 8, 10, 21, 25, 29), and being called on in language class by the teacher (items: 3, 12, 20, 33). T-test was used to compare the total score of each category with the students' language proficiency level. Among the six sources of anxiety, only the third reason (making mistakes) has a significant difference with the students' language proficiency level. There is no statically significant difference between the proficiency levels and the other sources of language anxiety.

Table 3. T-test results related to elementary and pre-intermediate Students' total score about making mistakes

\begin{tabular}{lcccccc}
\hline Proficiency Level & Number & Mean & Standard Deviation & df & $t$ & $p$ \\
Elementary & 100 & 11,65 & 3.18 & 194 & 2,51 & 0,01 \\
& 96 & 12,77 & 3.03 & & &
\end{tabular}

Pre-intermediate

$\mathrm{P}<0.05$

The results show that the mean of the anxiety level of elementary level students about making mistakes is 11.65 , and the mean of the anxiety level of pre-intermediate level students about making mistakes is 12.77 . According to conventional criteria, the difference between two groups of students is statically significant $(\mathrm{p}<0.05)$. The reason that makes students the most anxious appears to be making mistakes. On the other hand, pre-intermediate level students' anxiety level about making mistakes appears to be higher than the elementary level students. The reason for this could be pre-intermediate level students' higher language perception and the feeling of competitiveness with their classmates, as it can be assumed that a pre-intermediate level student knows that his/her friends have the same perception about the language as him/her, and if he/she makes any mistakes, his/her friends are going to correct him or perhaps joke about him/her. This could be linked to what Jones (2004: 33) proposed: "... language anxiety has its origin in the fear of making mistakes and attracting the derision of classmates." Bailey's (1983) study on this aspect also seems to provide similar findings, as she found that competitiveness could cause anxiety and higher-level students might have this feeling among themselves to get positive feedback from their teacher (ibid.). Moreover, she states that the students might have concerns about their teachers' expectations. Her last emphasis, on the other hand, seems to be on the fact that as the proficiency level goes up, the language becomes more complex, and grasping the language becomes difficult, consequently worrying the learners (ibid.). 


\section{Macrothink}

Similar findings were also obtained in a study by Marcos-Llina's and Garau (2009) in Spain. They applied FLCAS to 134 college students of three different proficiency levels, and the results showed that the higher the proficiency level is, the higher the speaking anxiety level it is (Marcos-Llina's and Garau, 2009).

The results of the t-test which was carried out to compare the total score of each category of sources with the students' proficiency level show that the students with high proficiency level feel more anxious than students with low proficiency level.

3.1.3 EFL Students' Varying Levels of FLA with regard to Proficiency Level and Gender (Research question 3)

Table 4. T-test result of speaking anxiety level with respect to the students' proficiency level

\begin{tabular}{lcccccr}
\hline Proficiency Level & Number & Mean & Standard Deviation & df & $t$ & $p$ \\
Elementary & 100 & 94.86 & 17.11 & 194 & 2.05 & 0.04 \\
& 96 & 99.64 & 15.40 & & &
\end{tabular}

Pre-intermediate

$\mathrm{P}<0.05$

Table 4 shows that the mean of the anxiety levels of elementary level students is 94.86 and that of pre-intermediate level students is 99.64 . The significance level is 0.04 , which means the difference is considered to be statically significant. This could be because pre-intermediate level students are more anxious than elementary level students; the higher the levels of the students, the more concerns they have about their teachers' expectations. In addition, as the proficiency level goes up, the language becomes more complex, so the understanding of the language becomes difficult, which worries the learners.

Contrary to the expectations, the results of the test that was conducted to compare the elementary and pre-intermediate students' anxiety level show that pre-intermediate level students' anxiety level is higher than that of elementary level students.

Table 5. T-test result of speaking anxiety level with respect to the students' gender

\begin{tabular}{lcccccc}
\hline Gender & Number & Mean & Standard Deviation & df & $t$ & $\mathrm{p}$ \\
Female & 57 & 95.05 & 18.29 & 194 & 1.17 & 0.27 \\
& 139 & 98.08 & 15.59 & & & \\
Male & & & & & & \\
\hline
\end{tabular}

$\mathrm{P}>0.05$ 


\section{Macrothink}

According to Table 5, the mean of the anxiety level of female students is 95.05 and that of male students is 98.08. Because the level of significance is 0.27 ( $p>0.05)$, the difference is considered to be not statically significance. The results show similarity with the results of the studies conducted by Campbell (1999) and Dewaele (2002).

\subsection{Findings from the Interview Data}

This section presents findings related to the interview data.

\subsubsection{EFL Speaking Anxiety}

Although the questionnaire findings showed that most of the students had low level of anxiety while speaking English, the detailed data obtained from the interviews indicated that six out of 10 participants who participated in the interviews suggest that speaking is an anxiety-provoking factor in the foreign language learning process. Participants stated their thoughts as follows (echoing the majority):

"When I have to speak, I get nervous and make a lot of mistakes, so I do not want to speak again."

Interviewee 3

"Speaking makes me anxious. I think I have to speak perfectly when I speak, and I do not think that I am perfect about speaking."

Interviewee 5

"Especially when the teacher asks a question to me, I get nervous because I am never sure about whether I understand the question correctly."

Interviewee 8

"Speaking in front of my classmates makes me anxious because I do not believe that my pronunciation is good enough, so I think they will laugh at me."

Interviewee 7

The quotations given above reflect the majority of the participants' feeling of anxiety toward speaking in the target language, especially as a result of the 'fear of making mistakes', 'being laughed at', and 'perfectionism'. These findings show similarities with that of Young's (1991), who also presented three factors that affected foreign language learning: the learner, the teacher, and the institution. In the present study, the participants' responses can be related to Young's learner factor (i.e., their anxiety seems to be due to their characteristics, such as low self-esteem (Interviewees 7 and 8).

In the present study, only three of the participants stated that EFL speaking is not an anxiety-provoking factor. The following quotations represent these participants' responses:

"I do not believe that speaking English is an anxiety-provoking factor because we are all learners and making mistakes is not a problem." 
Interviewee 1

"Speaking English does not make me nervous because I focus on only what I want to say, not to the rules or other people around me."

Interviewee 4

"I do not feel nervous when I am speaking in the classroom because I know that my teacher is not interested in my mistakes but interested in what I am saying."

Interviewee 10

The above comments perhaps reflect the views of the participants who have high self-esteem. The comments made by Interviewees 1 and 4 are clear in the sense that they are not afraid of making mistakes; thus, perhaps they are less anxious about being laughed at, as they see making mistakes while learning as part of the process - as something normal. On the other hand, the comment made by Interviewee 10 may address the teacher factor. Interviewee 10 seems to have developed a sort of self-confidence, which is likely to decrease her anxiety level, possibly because her teacher does not interrupt or criticize her when she makes mistakes.

\subsubsection{Sources of and Reasons for Speaking Anxiety}

When the participants were asked about the reasons that made them anxious, "speaking in front of the class," "not understanding the question asked by the teacher," "being unprepared," "being asked immediate questions," and "lack of skill in pronouncing the words correctly" appeared to be the most cited reasons. Among these, "being unprepared" and "being asked immediate questions" were the first two among the others. The following are the comments made by the participants that are representative of the overall cohort:

"If I am not prepared well to speak, I get so nervous. Especially when the teacher suddenly asks me a question, I forget every single word I know and start to make sound like 'err'... or 'mmm' ..."

Interviewee 9

"If I do not have a good command of the subject and know what to say, it makes me anxious. I want to be $100 \%$ sure before I start to speak."

Interviewee 8

The above comments may indicate how important it is for the participants to be well-prepared to speak in the target language. Although it is not cited by the participants explicitly, since the participants do not have sufficient language proficiency level, they seem to need to think what to say first before speaking up, which is perhaps something again related to avoiding making errors in the classroom. That is to say, although "not being prepared well" seems to be the prominent theme mentioned by the participants of this study, this could again be linked to what Young (1991) found about the most anxiety-provoking factor-talking in front of others. 
When the participants were further questioned about the reasons making them anxious, the following factors emerged. The following reasons are given in order of the number of the citations from the interviews, from highest to lowest:

- I do not have enough practice in speaking.

- I did not have a good English education before university.

- I am afraid of making mistakes.

- I do not trust myself while speaking English.

- I am afraid of potential reactions of the other students regarding my speaking performance.

Among the above factors, fear of making mistakes is a widely accepted and acknowledged factor in the literature. Many studies (i.e., Jones, 2004), for example, noted that fear of making mistakes affects foreign language learning negatively, and it slows down the process of learning. This finding was also the most striking one in the questionnaire data of the present study, in which it was noted that making mistakes was the factor causing anxiety which had a significant relationship with the learners' language proficiency level. These findings seems to be confirmed by the interview findings as well. The other sources of anxiety emerging from the present study as given in the above list seem to be similar to the ones that exist in the literature, except previous education in the English language and having less practice in speaking the English language. Having less practice in speaking the English language can perhaps be linked to not having sufficient language proficiency level. Having no previous English language education, on the other hand, can perhaps be viewed in terms of "getting used to making mistakes." What participants meant can perhaps be linked to their greater fear of making mistakes as they are more unsure about the reactions of the teacher and the classroom; consequently, they have more concerns about it. On the other hand, the participants who spent more time learning English may have experienced such situations previously, and they are more aware of what the outcomes would be when they make mistakes.

\section{Conclusion}

The present study was undertaken to investigate speaking anxiety of Turkish and Turkish Cypriot students in the English language, which they were learning as a foreign language at the time this study was conducted. The study primarily intended to explore EFL students' anxiety levels and the sources that made the students most anxious, as well as to find out the potential relationship between FLA levels of the students and their proficiency levels and genders.

The findings of the study from the questionnaire data revealed that the students generally had low level of EFL speaking anxiety. Among the factors that made students the most anxious, making mistakes was the most prominent one. The interesting aspect here, however, was that the students with higher level of language proficiency were found to be more anxious than lower level students. When the findings of the study and the existing findings in the literature were considered, this issue could be linked to the issue of competitiveness between the 
classmates and classroom teachers' expectations of the higher level students. As the existing findings in the literature guide us to assume that with increasing levels, competitiveness to not make mistakes in the classroom becomes a serious issue, and the expectations of the teachers increase (Jones, 2004; Marcos-Llina and Garau, 2009). The anxiety level-gender relationship, on the other hand, yielded no statistically meaningful relationship in the present study.

In the study, anxiety and self-esteem relationship seemed to appear, as the students who seem to have high or moderate level of anxiety have more fear of being laughed at by their classmates, which is likely to trigger their anxiety levels. Evidence for the opposite was also present in the study.

Detailed views of the participants from the interviews with regard to the sources of speaking anxiety seemed to provide us with new findings that would enrich the literature. Not understanding the question asked by the teacher, being asked immediate questions by the teacher, the need to get prepared to speak, lack of skill in pronouncing the words, and not having a good English education before the current university seem to be the factors that appear to be new findings, compared with the existing studies. The reason behind these new findings could be the qualitative method employed in the present study, whereas the majority of the existing studies explore the phenomenon with quantitative methods. Although the questionnaire data revealed a generally low anxiety level among the participants of the study, the majority of the participants in the interviews clearly mentioned that speaking in the foreign language was an anxiety-provoking issue.

\section{Implications}

The first implication of the present study is that language teachers should be aware of the possible presence of language anxiety in their classes, otherwise their teaching methods might be hampered by unwilling learners who experience anxiety. Second, program or curriculum designers should consider enriching the types of activities and tasks to be implemented in classrooms, such as by encouraging more cooperative activities that would result in a positive classroom environment. Third, because of the fear of making pronunciation-related mistakes and the feeling of anxiety with regard to immediate speaking instances, as observed in the present study, program designers could consider increasing such practice-based tasks and make students more used to such occasions. Finally, teachers must consider the occasions and difficulties students may face while speaking in the foreign language and try to keep this at the minimum by employing various strategies.

\section{References}

Arnaiz, P., \& Guillén, F. (2012). Foreign Language Anxiety in a Spanish University Setting: Interpersonal Differences. Revista de Psicodidáctica, 17(1), 5-26.

Bailey, K. M. (1983). Competitiveness and anxiety in adult second language learning: Looking at and through the diary studies. In H. W. Seliger \& M. H. Long (Eds.), Classroom-oriented research in second language acquisition (pp. 67-102). Rowley, MA: Newbury House. 


\section{Macrothink}

International Journal of English Language Education

ISSN 2325-0887 2016, Vol. 4, No. 1

Bless, H., \& Fiedler, K. (2006). Mood and the regulation of information processing and behavior. In J. P. Forgas (Ed.), Affect in social thinking and behaviour, (pp. 65-84). New York: Psychology Press.

Campbell, C. M. (1999). Language anxiety in men and women: dealing with gender difference in the language classroom. In D. J. Young (Eds.), Affect in Foreign Language and Second Language Learning (pp. 191-215). New York: McGrew Hill.

Cohen, L., Manion, L., \& Morrison, K. (2011). Research methods in education (7 ed.). New York: Routledge.

Creswell, W., J., \& Clark, P., L., V. (2006). Designing and Conducting Mixed Method Research. Sage Publication.

Deweale, J. M. (2002). Psychological and sociodemographic correlates of communicative anxiety in L2 and L3 production. The International Journal of Bilingualism, 6, 23-29. http://dx.doi.org/10.1177/13670069020060010201

Gardner, R. C., \& MacIntyre, P. D. (1993). A student's contributions to second language learning. Part II: Affective variables. Language Teaching, 26, 1-11. http://dx.doi.org/10.1017/s026144 4800000045

Hedge, T. (2011). Teaching and Learning in the Language Classroom. Oxford University Press.

Horwitz, K., E. (2001). Language Anxiety and Achievement. Annual Review of Applied Linguistics, 21, 112-126. http://dx.doi.org/10.1017/s0267190501000071

Horwtiz, K., E., Horwitz, B., M., \& Cope, J. (1986). Foreign Language Classroom Anxiety. The Modern Language Journal, 70(2), 125-132. http://dx.doi.org/10.2307/327317

Kvale, S. (2007). Doing Interviews. Thousand Oaks, CA: Sage.

Liu, M. (2006). Anxiety in EFL Classrooms: Causes and Consequences. TESL Reporter, 39(1), 13-32.

Lucas, I., R., Miraflores, E., \& Go, D. (2011). English Language Learning Anxiety Among Foreign Language Learners in Phillippines. Philippine ESL Journal, 7, 24-37.

Marcos-Llins, M., \& Garau, J., M. (2009). Effects of Language Anxiety on Three Proficiency-Lvel Courses of Spanish as a Foreign Language. Foreign Language Annals, 42(1), 94-111. http://dx.doi.org/10.1111/j.1944-9720.2009.01010.x

Minghe, G. \& Yuan, W. (2013). Affective Factors in Oral English Teaching and Learning. Higher Education of Social Science, 5(3), 57-61.

Ohata, K. (2005). Potential sources of anxiety for Japanese learners of English: Preliminary case of interviews with five Japanese college students in the US. TESL-EJ, 9(3), 2-23

Ormrod, E. J. (2005). Essentials of Educational Psychology. Pearson. 


\section{Macrothink}

Öztürk, G., \& Gürbüz, N. (2014). Speaking anxiety among Turkish EFL learners: The case at a state university. Journal of Language and Linguistic Studies, 10(1), 1-17.

Ün, E. (2012). Sources \& Levels of Foreign Language Anxiety In Turkish University Students Relative To; Language Proficiency, Intentions For Use And Perceived Barrier. (un)published MA Thesis.

Young, J. D. (1991). Language Anxiety from the Foreign Language Specialist's Perspective: Interviews with Krashen, Omaggio Hadley, Terrell and Rardin. Paper presented at the Annual Meeting of the Central States Conference on the Teaching of Foreign Languages.

Young, J. D. (1994). New Directions in Langauge Anxiety Research. In Faces in a Crowd: The Individual Learner in Multisection Courses. Heinle and Heinle Publisher.

Yule, G. (2006). Study of Language (3rd eds). Cambridge University Press.

Williams, K. E., \& Andrade, M. R. (2008). Foreign language learning anxiety in Japanese EFL university classes: Causes, coping, and locus of control. Foreign Language Teaching, $5(2), 181-191$.

Wörde, V., R. (2003). Students' Perspectives on Foreign Language Anxiety. Inquiry, 8(1), 57-68.

\section{Copyright Disclaimer}

Copyright for this article is retained by the author(s), with first publication rights granted to the journal.

This is an open-access article distributed under the terms and conditions of the Creative Commons Attribution license (http://creativecommons.org/licenses/by/3.0/). 